\title{
FANTASMAS DA INFÂNCIA: CRIANÇA QUEER E (IN)VISIBILIDADE EM PARANORMAN E PLUFT, O FANTASMINHA
}

\author{
Israel Augusto Moraes de Castro Fritsch ${ }^{1}$ \\ A formação de um sujeito requer identificação com o fantasma narrativo do 'sexo'. \\ JUDITH BUTLER Corpos que Importam \\ A infância é uma canoa que naufraga/ e a bordo não traz senão fantasmas. \\ IVAN JUNQUEIRA A Sagração dos Ossos
}

\begin{abstract}
Vocês me dão agora o privilégio de falar da coragem de ser eu mesmo depois de me terem feito carregar o peso da exclusão e da vergonha por toda a minha infância. (...) Mas vocês nunca vão se cansar de ficar sentados diante da nossa 'coragem' como quem se senta diante de um divertimento?

PAUL B. PRECIADO Um apartamento em Urano
\end{abstract}

RESUMO: Norman e Pluft, personagens do filme e livro ParaNorman e da peça Pluft, o Fantasminha, respectivamente, estão localizados entre o mundo e o além-mundo como alegorias para uma infância fora do padrão. Ao longo das narrativas, eles precisam ser aceitos pelo que compartilham de distinto e não de semelhante, em relação às demais crianças ou familiares. É possível ler Norman, o menino paranormal, como um ser "monstrificado", pela abjeção com que é compreendido pela comunidade, apesar de não apresentar deformação física. Já Pluft inverte o papel de fantasma, cobrado pela mãe em relação aos humanos que deveria assustar, mas é por estes assustado: um fantasma medroso. Defende-se que, no contexto da infância queer, esses personagens "nasce[m] nessas encruzilhadas metafóricas, como a corporificação de um certo momento cultural - de uma época, de um sentimento e de um lugar" (COHEN, 2000, p. 26), para demostrar que há outros comportamentos possíveis.

PALAVRAS-CHAVE: infância; queer; monstros

ABSTRACT: Norman and Pluft, characters in the movie and book ParaNorman and in the play Pluft, o Fantasminha, are allegories for non-standard children. Throughout the narratives, they need to be accepted for what they share as distinct and not similar, in relation to other children or family members. Norman, the paranormal boy, is a kind of monster because he is not understood. Pluft, on the other hand, reverses the role of a ghost because it is a fearful ghost. In the context of queer childhood, these characters "are born at these metaphorical crossroads, as the embodiment of a certain cultural moment - a time, a feeling and a place" (COHEN, 2000, p. 26), to demonstrate that there are behaviors that not fit.

KEYWORDS: childhood; queer; monsters

\footnotetext{
${ }^{1}$ Jornalista. Doutorando do PPG em Letras da UFRGS.
} 
“- As pessoas falam, Sandra. Todo mundo sabe que ele não é normal." (KIMMEL, 2012, p. 37). "Maribel cutuca o fantasminha e acha graça de ele ser diferente dela." (MACHADO, 2009a, paginação irregular) [grifos meus]. Esses dois trechos, respectivamente, um diálogo e a rubrica de texto dramatúrgico, são parte das obras que serão analisadas neste artigo: o filme ParaNorman, lançado em 2012 e dirigido por Chris Butler e Sam Fell, e sua adaptação em livro homônimo, feita pela autora norte-americana de livros infantis Elizabeth Cody Kimmel, e a peça teatral Pluft, o Fantasminha, de Maria Clara Machado, que estreou no Rio de Janeiro em 1955 e, além de ter sido publicada em livro como dramaturgia, também foi adaptada para prosa pela autora. A proposta é discutir como os dois personagens, Norman e Pluft, estão localizados em um ponto incompreendido entre o mundo e o além-mundo como alegorias $^{2}$ para uma infância fora do padrão e que, ao longo da narrativa, precisam deixar de (se) assustar com os humanos e serem aceitos pelo que compartilham de distinto e não de semelhante, em relação às demais crianças e aos familiares.

A intenção deste trabalho também é avançar no questionamento da padronização imposta a essas crianças "não normatizadas", para além da questão de orientação sexual ou expressão de gênero que atravessa grande parte da teoria queer. Quer dizer, há outros comportamentos caracterizados no contexto cultural que compartilham dessas experiências de violência/incompreensão por inadequação e, nos casos de Norman e Pluft, adentram a estética do gótico no diálogo com o desconhecido: desconhecido que assusta, o sobrenatural. Assim, a comunidade não identifica a demanda dessas crianças no processo de inserção e visibilidade e, além disso, repreende-as. Personagens de outras obras transversais também serão destacados neste contexto.

É possível ler Norman, o menino paranormal, como um ser "monstrificado" aos olhos da comunidade, que não compreende sua capacidade de comunicação com os mortos. Norman não carrega uma deformação peculiar aos monstros, mas é considerado como se a tivesse, tanto que é chamado de aberração, adjetivo identificado com a teratologia. $\mathrm{O}$ fantasma Pluft rechaça a ideia de ser um monstro, como veremos, mas se revela deslocado do seu caráter fantasmático porque tem medo de humanos, quando o esperado a um fantasma seria o contrário, ao desenvolver a capacidade de assombrá-los, o que é recorrente nas histórias infantis. É essa inversão do senso comum que marca a dramaturgia de Maria Clara Machado.

\footnotetext{
2 "Por meio da alegoria, ideias ou realidades abstratas ganham representação concreta, geralmente por meio de narrativas (...)." (p. 485). AZEREDO, José Carlos de. Gramática Houaiss da Língua Portuguesa. São Paulo: Publifolha, 2014.
} 
Entende-se o termo queer, que se tornou flexível e passa por permanente análise, no sentido de esquisito, e o esquisito só é identificado diante da linguagem excludente da norma, que estabelece um falso normal relacionado à homogeneização imposta durante a infância, através das classificações de sexo e gênero e implicação de padrões pré-estabelecidos pelos binarismos heteronormativos $^{3}$ : menino-menina, homem-mulher, heterossexual-homossexual, corajoso-medroso, louco-lúcido, humano-não humano, humano-animal etc. - que excluem outras possibilidades. As histórias de Norman e Pluft foram feitas para o público infanto-juvenil e expõem essas crianças dissonantes, destoadas da padronização dos pares: par que forma o binário e par como sinônimo do igual.

A palavra de Língua Inglesa queer foi adotada política e academicamente como categoria afirmativa de expressão de gênero entre as décadas de 1980 e 1990, mas já existia desde o século $\mathrm{XVI}^{4}$, no sentido de algo perverso, que, posteriormente, no final do século $\mathrm{XIX}^{5}$, serviu como gíria ofensiva usada para descrever e injuriar homossexuais, quando ainda não havia um leque de categorias relacionadas à identidade de gênero. $\mathrm{O}$ termo passou a ser consumido pelo movimento gay norte-americano no intuito de descaracterizá-lo enquanto ofensa e acabou contrapondo-se ao próprio termo gay como alternativa que abarca todo um conjunto de pessoas aquém da heteronormatividade e de uma certa homossexualidade que espelha comportamentos heteronormativos. O queer político é "a recusa dos valores morais violentos que instituem e fazem valer a linha da abjeção, essa fronteira rígida entre os que são socialmente aceitos e os que são relegados à humilhação e ao desprezo coletivo. (MISKOLCI, 2013, p. 24).

Mas não é de hoje que se questiona a aplicabilidade do termo queer. Anzaldúa (1991) afirmou, quando o queer ainda se constituía como teoria, que o conceito era "usado como um falso guarda-chuva sob o qual todos os 'esquisitos' de todas as raças, etnicidades e classes estavam enfiados." (p. 164) ${ }^{6}$. Por outro lado, para usar uma sugestão feita ao movimento negro por Audre Lorde (2019), "se nós não nos definirmos, seremos definidos pelos outros.” (p. 46). Nesta amplitude e flexibilidade de interpretação do conceito, o queer se aproxima do gótico como categoria maleável (HOGLE, 2011, p. 2), com algumas características que permitem a

\footnotetext{
${ }^{3}$ Apesar de ainda não estar dicionarizada, como já está consagrada, optei por usá-la sem a distinção de neologismo, que requer aspas. São variantes heterocisnormatividade ou cis-heteronormatividade, que agregam ao termo a ideia de exclusão de corpos transexuais. Heteronormatividade é uma atualização de heterossexismo, também não dicionarizado.

${ }^{4}$ Queer. In: Oxford Learner's Dictionary. Disponível em

https://www.oxfordlearnersdictionaries.com/definition/english/queer_1?q=queer. Acesso em 22 de ago. 2020.

${ }_{5}^{5}$ Queer. In: Lexico.com. Disponível em https://www.lexico.com/definition/queer. Acesso em 22 de ago. 2020.

${ }^{6}$ Tradução minha para "Queer is used as a false unifying umbrela which all 'queers' of all races, ethnicities and classes are shoved under."
} 
classificação ou a leitura de obras a partir destas concepções de comportamento e/ou estética. Se a aplicabilidade da ideia do queer nos personagens Norman e Pluft é o propósito deste trabalho, não há dúvida de que as obras em questão pertencem à seara do gótico. Se se constitui como gótico, no amplo rol das evidências, histórias com segredos do passado que assombram seus personagens, isto já incluiria ParaNorman e Pluft, o Fantasminha no contexto da ficção desde gênero.

\section{Norman, bullying e a família}

Em português e inglês, respectivamente, os termos "norma" e "norm" têm a mesma origem latina e significam a imposição de um modelo, regra ou comportamento a ser seguido/reproduzido. Norman, protagonista do filme ParaNorman - trocadilho feito com o nome do menino e palavra "paranormal"7, remete à essa mesma raiz propositalmente, para evidenciar que essa criança norte-americana de onze anos age de forma estranha à esperada para um menino de sua idade, mas, ao fim e ao cabo, na mensagem inclusiva da obra, também é normal, porque é normal ser diferente.

Norman é afeito a ver e conversar com fantasmas e aprecia filmes e temas de terror, dentro de um clichê gótico contemporâneo de aficionados pela estética da morte e do medo. Logo no início do longa-metragem, o menino conversa com a avó, já falecida e que só ele enxerga, e é repreendido pelo pai - liberal e rude - por suas esquisitices. O garoto segue para a escola, dialogando com os fantasmas que encontra na rua e já lhe são conhecidos. Ao chegar ao colégio, Norman depara-se com a palavra "aberração"8 vandalizada na porta do seu armário, um clássico exemplo de bullying nas instituições de ensino norte-americanas. Segundo a teórica queer Eve Sedgwick, o armário, metafórico não apenas no contexto LGBTQIA+, é um espaço de performance de segredo e de revelação permanentes sobre a orientação sexual:

O armário não é uma característica apenas das vidas das pessoas gays. Mas, para muitas delas, ainda é a característica fundamental da vida social, e há poucas pessoas gays, por mais corajosas e sinceras que sejam de hábito, por mais afortunadas pelo apoio de suas comunidades imediatas, em cujas vidas o armário não seja ainda uma presença formadora." (SEDGWICK, 2007, p.22).

Sedgwick defende que, por mais que a pessoa force uma saída do armário, outras circunstâncias, como um novo emprego, a chegada a uma cidade, uma apresentação em público,

\footnotetext{
${ }^{7}$ Igualmente escrita nas duas línguas.

${ }^{8}$ Freak no original.
} 
colocarão o "assumido" de volta ao armário para que saia mais uma vez. No caso de Norman, o armário, literalmente, serve de cartaz para a exposição pública, por parte dos colegas, que o cotejam fora da norma para um menino do sexo masculino, como uma aberração. O líder do grupo de valentões aparece com seu séquito e, ao agredir Norman verbalmente, chama o menino de "fantasma idiota". A perseguição, ainda nesta primeira parte da história, reforça a posição menorizada de Norman diante das demais crianças, amplificada na escola, um grande e permanente armário, palco tradicionalmente entendido como

o primeiro espaço de aprendizado da violência de gênero e sexual. (...) um campo de batalha para o qual são enviadas as crianças, com seu corpo delicado e seu futuro em branco como únicas armas (...). Que importam os idiomas ensinados, se a única língua que se fala ali é a violência secreta e surda da norma? [grifo meu]. (...) A escola potencializa e valoriza a teatralização convencional dos códigos da soberania masculina no menino e da submissão feminina na menina, ao mesmo tempo que vigia o corpo e o gesto, castiga e patologiza toda forma de dissidência." (PRECIADO, 2020, p. 192).

Ser aberração é não corresponder à figura esperada. Portanto, em casa, onde a violência pode ser um pouco mais diluída, ou na escola, sem filtros, Norman sofre intimidações. Não se encontra nele deformação aparente, mas o fato de ele ver mortos deforma-o diante dos demais. A família de Norman, branca, de classe média baixa, vive no subúrbio de uma cidade fictícia chamada Blithe Hollow, na região de New England, que remete à Salem, onde um acontecimento real envolveu meninas e marcou a História dos Estados Unidos:

Em 1692, a Colônia da Baía de Massachussetts executou por bruxaria catorze mulheres, cinco homens e dois cachorros. (...) Rica em seres humanos que mudam de forma, voos fantásticos, madrastas más e feno enfeitiçado, a crise de Salem é parecida com outro gênero do século XVII: o conto de fadas. (...) Um grupo de meninas muito jovens, privadas de direitos, desencadeou a crise, revelando forças que ninguém podia conter e que ainda hoje espantam - que podem ou não ter algo a ver com a razão para se transformar uma história de mulheres em perigo numa história de mulheres perigosos. (SCHIFF, 2019, paginação irregular).

Assim, Blithe Hollow tem como fonte de renda o turismo que explora a lenda da mulher enforcada pelos colonizadores puritanos 300 anos atrás, acusada de bruxaria e que teria amaldiçoado a cidade; depois, descobre-se que a bruxa era, na verdade, uma menina, Aggie Prenderghast, que também fora "monstrificada" pela comunidade puritana e tinha os mesmos dons mediúnicos de $\operatorname{Norman}^{10}$, porque era sua parente.

\footnotetext{
${ }^{9}$ Ghost jerk no original.

${ }^{10}$ Criança com paranormalidade é recorrente na literatura e no cinema norte-americanos. O clássico do terror $O$ Iluminado, escrito por Stephen King, tem como personagem o menino Danny, que também vê fantasmas e desenvolve o poder da premunição. A sequência desta história, Doutor Sono, escrita pelo mesmo autor, também mostra uma menina, Abra, com os mesmos dons. Ambos os livros foram adaptados para o cinema. No filme O Sexto Sentido, lançado em 1999, o menino Cole Sear, considerado uma criança perturbada, diz a famosa frase "I see dead people", que se torna o ponto de virada da história.
} 
O garoto sensitivo - esta é uma palavra-chave importante para a história, visto que, em inglês, "sensitive" significa alguém sensível, mas também uma pessoa com poderes extrassensoriais -, em um dos momentos de discussão com o pai, diz-lhe que não pediu para nascer assim ${ }^{11}$, paranormal, ao que o homem lhe responde que nem ele havia pedido para ter um filho desse jeito. A conversa causa uma ruptura. A mãe tenta amenizar, dizendo a Norman que às vezes as pessoas falam coisas cruéis porque têm medo ${ }^{12}$; o menino responde que se trata do pai, que não poderia ter medo do filho ${ }^{13}$. O medo, que é um dos efeitos do ato do fantasma diante do assombrado, vem do pai, vivo, e não dos fantasmas que interagem ou perseguem Norman. O próprio Norman só teme os espíritos relacionados à maldição que precisa interromper, mais pela atribuição que lhe recai sobre os ombros e que precisa assumir sozinho, salvar cidade da suposta bruxa, do que por reação ao fantasmático. Em uma cena com a falecida avó, Norman ouve dela uma lição: "não há nada de errado em estar assustado, desde que isto não mude quem você é"14 ${ }^{14}$ reforçando a valorização da identidade esquisita do menino e que ele é assombrado não apenas pelos fantasmas da histórica maldição, mas também pela comunidade, incluindo os parentes vivos. Note-se que é um fantasma, a avó, que compreende Norman dentro do círculo familiar, porque é parte da prova do dom sensitivo do menino, ao passo que pai, mãe e irmã, não tendo a experiência da paranormalidade, não lidam bem com a estranheza. A avó de Norman (figura1), personagem de animação criado pela técnica de stop motion, é bastante parecida, não apenas no comportamento, a uma outra avó do cinema, que também serve de esteio para o neto queer. Trata-se da personagem Élisabeth (figura 2), avó do menino Ludovic Fabre. Ele se reconhece como menina, e este é o dilema da obra de 1997 Minha Vida em Cor-de-Rosa ${ }^{15}$, dirigida por Alain Berliner. O filme discute a questão da transexualidade na infância sem tocar no assunto diretamente e, assim como no caso de Norman, a pressão da sociedade e dos familiares sobre Ludovic é equilibrada pela figura da avó compreensiva. Como em ParaNorman, essa película também apresenta a fantasia como estética para tratar do tema do desvio.

\footnotetext{
11 "I didn't ask to be born this way!" no original. Born this way é o nome de um álbum e de uma canção da cantora pop americana Lady Gaga, lançados um ano antes do filme, em 2011, em que o eu-lírico diz: "não há outro jeito [de ser], porque nasci assim". A cantora tinha um estilo gótico moderno, fazendo da vestimenta e da maquiagem bizarras parte da pose de imposição e valorização do esquisito, como acontece no filme ParaNorman. Como produto cultural, ela se identifica com a comunidade queer e chama os fãs de little monsters ("monstrinhos"). Em uma rede social, Gaga (2018) disse: "To every little monster on the planet who feels different. So do I. And we have each other." ("Para cada monstrinho do planeta que se sente diferente. Também eu me sinto. E nós temos uns aos outros.”) [traduções minhas].

12 " $Y$ 'know, sometimes people say things that seem mean, but they do it because they're afraid."

13 "He's my dad. He shouldn't be afraid of me."

14 "There's nothing wrong with being scared Norman, so long as you don't let it change who you are."

${ }^{15}$ Nome original: Ma vie en Rose.
} 
Figura 1

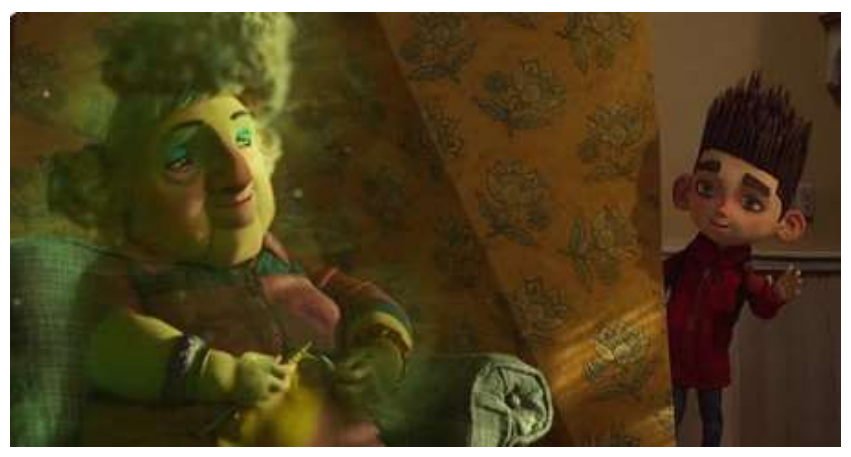

Figura 2

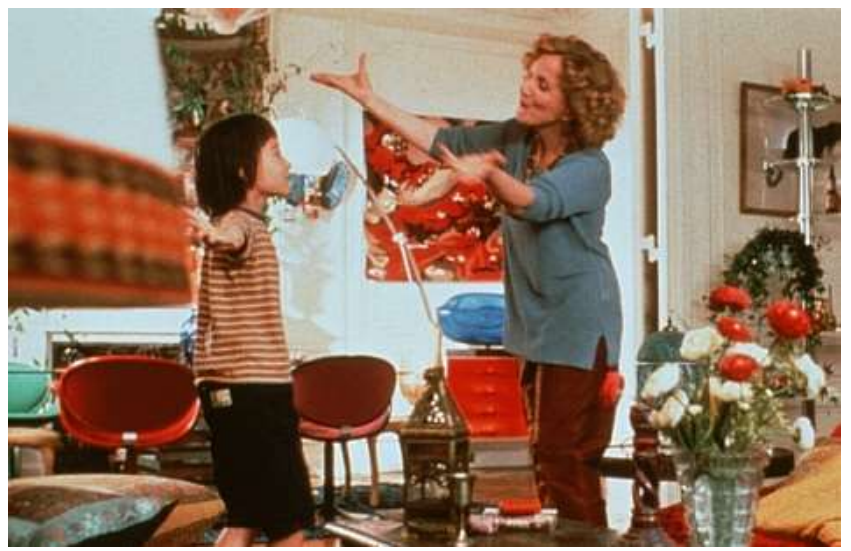

Portanto, a falta de lucidez dos parentes de Norman é similar à de familiares intransigentes com outras crianças queers que não respondem às imposições normativas de comportamento que devem representar o sexo de nascimento correspondente ao gênero previsto, conforme os padrões político-culturais de cada território: “Os defensores da infância e da família invocam a figura política de uma criança que eles constroem de antemão como heterossexual e de gênero normatizado.” (PRECIADO, 2020, p. 62).

\section{O tio esquisitão}

Através de um tio-avô igualmente esquisito, que vive isolado e é aparentemente solteiro, Norman acaba por descobrir que o parentesco com a bruxa da suposta lenda dá ao tio e ao próprio Norman poderes para acabar com a maldição que ameaça a cidade de Blithe Hollow. O tio chama-se Mr. Prenderghast, nome que parece ser feito da junção do verbo português "prender" com "gast" ou "gāst", palavras que deram origem à anglófona "ghost", fantasma em português. O controle da maldição deve ser renovado todo ano e por alguém com poderes extrassensoriais, como os dos dois, tio-avô e sobrinho-neto. A pessoa com esse dom precisa ler 
uma história no túmulo para que a menina-bruxa permaneça adormecida e não acorde para efetivar a maldição vingativa por ter sido executada pelos puritanos/justiça local. Mr. Prenderghast realizou a tarefa de "prender o fantasma" no túmulo por 50 anos. Velho, ele tenta repassar a Norman a empreitada para evitar que a menina acorde e, finalmente, como prevê a lenda, vingue-se. Porém, Mr. Prenderghast morre antes de Norman aceitar a tarefa, que o menino não compreende bem. Como o fantasma do pai de Hamlet, o espectro do tio persegue o menino para que este desfaça a maldição e não comprometa toda a cidade caso a vingança da menina realmente aconteça.

Ao final do filme/livro, Norman torna-se um herói ao controlar a maldição da bruxa, que não era apenas uma lucrativa lenda para a municipalidade, mas uma história real, e, ainda, ela não era uma bruxa como denunciada pelo folclore, mas uma criança enforcada injustamente pela comunidade, como acontecera em Salem. Ele acaba por ouvir a menina, compreender a injustiça da qual ela foi vítima e apazigua seu rancor secular, para que ela volte para o mundo dos mortos, definitivamente.

A mensagem é de aceitação do outro ao tematizar a inclusão, a alteridade e a diferença. Além do pai intransigente, permanentemente envergonhado pelo comportamento do filho paranormal em público, e do clássico menino protegido pela avó, há outros indicativos que enfatizam a história como alegoria de uma criança queer.

No livro já citado, ParaNorman, que adapta o roteiro original de Chris Butler, a cena inicial, que não aparece no filme, narra o nascimento de Norman e mostra evidências que rementem à questão de gênero:

\footnotetext{
No dia em que Norman Babcock nasceu, coisas estranhas aconteceram. Norman ouviu algumas histórias do dia do seu nascimento de sua própria mãe: como as luzes na ala da maternidade explodiam no exato momento que o médico anunciou, "É um menino!"; como os cachorros do outro lado da cidade começaram a uivar num estranho coro na mesma hora; e como dois caras saindo do turno no Witchy Weiner viram um arco-íris no céu, o que poderia não ser estranho mas acaba ficando quando você acrescenta os detalhes: era uma hora da manhã e o arco-íris tinha a forma de um ponto de interrogação gigante... (KIMMEL, 2012, p. 9).
}

Os acontecimentos aludem à paranormalidade de Norman, mas, na entrelinha, sugerem um questionamento em relação à constituição do gênero do bebê. Dentro do hospital, a autoridade médica promove o poder que lhe é concedido pela ciência de fazer o enunciado performativo inaugural do sexo/gênero da criança. $\mathrm{O}$ mesmo enunciado será repetido inúmeras e das mais distintas formas dali em diante, por outras instituições constitutivas do sujeito. Enquanto o médico brada que é um menino, no lado de fora, aparece um arco-íris, símbolo de 
resistência do movimento LGBTQIA+, em forma de interrogação gigante que questiona a medicina, como contraponto

[à] força do performativo [que] resulta da imposição violenta de uma norma que preferimos chamar de natureza para não ter de enfrentar a reorganização das relações sociais de poder que uma mudança de convenções implicaria. (PRECIADO, 2020, p. 126).

Vários trechos do livro aludem ao comportamento desajustado de Norman, com frases que podem ser encaradas como reação/revelação à/da sensibilidade do menino: “O sr. Babcock [o pai] odiava quando Norman não agia como uma pessoa normal.” (KIMMEL, 2012, p. 21); "Nos onze anos que estava habitando este planeta, Norman tinha se tornado um perito em passar despercebido, escondendo sua verdadeira personalidade." (KIMMEL, 2012, p. 31).

Logo no início do filme, Norman ensaia na escola a montagem teatral anual em alusão à maldição da cidade - a mesma maldição que, mais tarde, ele irá combater efetivamente. Mesmo sabendo que pode falar com fantasmas, ele se assusta durante o ensaio porque a maldição mostra-se real, no palco, apenas para ele, misturando os personagens peregrinos com os fantasmas dos próprios peregrinos, que surgem para mostrar a Norman que havia um impasse verdadeiro a ser resolvido. Porém, os coleguinhas e a diretora do espetáculo não acreditam em Norman. Assim, a escola usa o teatro para enaltecer o folclore local, mas não compreende quando a História extrapola o fingido, denotando que se vive de aparências e que a realidade experimentada por Norman não é admitida, porque foge do previsto. O simulacro rende dividendos à cidade, mas quando passa a ser uma ameaça, com a aparição dos fantasmas, o cinismo impõe-se para não se ter de enfrentar o que está fora do roteiro social.

Para resolver a maldição, Norman conta com a ajuda da irmã adolescente, Courtney, do colega de escola, Neil, e do irmão de Neil, o também adolescente Mitch. Em uma das últimas cenas, durante os desdobramentos finais do filme, quando a história principal já está resolvida, Courtney convida Mitch para ir ao cinema. Mitch responde-lhe: "você vai amar meu namorado. Ele é louco por comédias românticas" ${ }^{16}$. Como reação, Courtney expressa a decepção que concretiza o castigo final à personagem que, ao longo do filme, comportou-se como uma menina mimada, uma espécie de antagonista, e, portanto, ficará sem o bonitão, que é gay; esta talvez seja uma das primeiras indicações positivamente explícitas ao homoerotismo em um filme infantil, em toda a história do cinema. Por trás desta gag está o fato de Mitch ter sido apresentado ao longo de todo o filme como o ideal adolescente do sexo masculino: forte,

16 "You're gonna love my boyfriend! He's like a total chick-flick nut!" 
apreciador de carros, valente etc. Na adaptação do filme em livro, ele é descrito como "um cara forte e poderoso, de pelo menos um metro e oitenta de altura, pelo que Norman podia calcular. A única coisa que ele tinha em comum com [o irmão menor] Neil era o cabelo ruivo. Mas em Mitch ficava bom”. (KIMMEL, 2012, p. 30). O adolescente Mitch é o contraponto aparentemente "normal" em relação aos esquisitos Norman e Neil - gordinho e, também, vítima de bullying na escola. Em um diálogo do filme reproduzido no livro, com uma pequena variação, o pai de Norman faz alusão ao tipo representado por Mitch: "por que você não pode ser como as outras crianças da sua idade e armar uma tenda no quintal ou ter um saudável interesse em carpintaria?" (KIMMEL, 2012, p. 30), ou seja, atividades que Mitch faria. ${ }^{17}$ Por isso, o pequeno ponto de virada do personagem mais próximo a um padrão social esperado a um rapaz surpreende ao desvendá-lo, para Courtney e à audiência, como alguém espontaneamente gay, apesar das aparências dentro da norma, evidenciando que não há padrão e que a expressão de gênero não é estanque.

O nome Norman remete ao protagonista de outro filme, o também esquisito Norman Bates, do clássico suspense dirigido por Alfred Hitchcock, Psicose ${ }^{18}$, de 1960, baseado no livro homônimo de Robert Bloch, publicado em 1959. De comportamento desviante, Norman, homem de 40 anos, administra o motel da família à beira de uma estrada secundária norteamericana. Ele age como a própria mãe, já morta, com quem supõe conversar e conviver, devido à sua dupla personalidade - algo muito próximo ao comportamento de Norman com a avó, que, no caso, é um fantasma de verdade e não resultado de uma patologia. A diferença é que, enquanto em ParaNorman a avó é uma aparição que equilibra a tensão entre Norman e o pai, a mãe do Norman de Psicose é que lhe serve de superego, com proibições, limitações, autoridade e desequilíbrio internos. Também, assim como o Norman da animação, o Norman de Psicose está mais próximo da morte ao praticar como hobby a taxidermia de pássaros (e da própria mãe, cujo corpo, desenterrado por ele, perece no porão da casa gótica, ao lado do motel da família). Nas primeiras sentenças do livro, que, ao contrário do filme, mantém o foco em Norman desde o início, este é descrito como medroso ao levar um susto pelo barulho da chuva, e alguém que prefere a organização da casa e a companhia de um bom livro ao trabalho, mote para a primeira aparição da mãe na narrativa a cobrar-lhe uma atitude, que vá atender no motel. A relação de Norman com a mãe imaginária - que, nas crises de dupla personalidade, chama-o de "garoto"19

\footnotetext{
${ }^{17}$ No original, no filme: "Can't you be like other kids your age and pitch a tent in the yard, or have a healthy interest in carpentry?".

${ }^{18}$ Psycho no original.

${ }^{19}$ Boy no original.
} 
- remete, ainda, à infantilização do personagem: "Não pode sair daqui... da mesma forma que também não pode crescer", a mãe diz-lhe no livro de Bloch (2013, p. 12). O homem adulto ainda se vê como menino amedrontado e perseguido pela mãe. Quando, nesta primeira cena, ele tenta escapar das cobranças da mãe-consciência, olha a janela e encontra, lá fora, "vento, chuva e escuridão. Ele sabia que não havia como escapar dali." (BLOCH, 2013, p. 12). "Dali” significa a relação de um homem esquisito e transtornado através do entendimento de si pelo viés da mãe, que lhe acusa de, desde a infância, ter medo das pessoas (o que também acontece com o fantasminha Pluft). Assim como o menino Norman, Norman Bates também sofrera bullying na infância ao ser chamado pelos coleguinhas de filhinho da mamãe: "Você é um maricas, um 'filhinho da mamãe", como a mãe-consciência lhe relembra. (BLOCH, 2013, p. 13). Além disso, tanto o Norman Babcock quanto o Norman Bates são descritos como sensitivos. Diz o narrador sobre Bates:

Quando se é um médium sensitivo, você sente as vibrações. (...) Tinha interesse por ocultismo e metafísica. Provavelmente acreditava em espiritualismo, assim como no poder de preservação da taxidermia. (BLOCH, 2013, p. 120).

Mas junto a isso e também por isso, diferentemente do menino Norman, cuja história passa-se 50 anos à frente, Bates é considerado doente pelo sistema jurídico-psiquiátrico:

Quando pensava na Mãe, ele voltava a ser criança, usava vocabulário de criança, referências e reações infantis. Mas quando estava sozinho, não; em verdade, não sozinho, mas afundado em um livro, era um indivíduo maduro. Maduro o suficiente para compreender que talvez fosse vítima de uma forma leve de esquizofrenia, ou provavelmente uma neurose na fronteira dela. (BLOCH, 2013, p. 80).

A psicose de Norman Bates é explicada pelo psiquiatra, que o atende ao final da história, como parte da relação doentia com a mãe, para justificar o comportamento queer do personagem. O médico suspeita que Norman travestia-se em segredo, antes mesmo de matar a mãe, por ciúmes do padrasto. Livro e filme são concluídos com uma explicação para o comportamento de Bates, legada à ciência. Continua o psiquiatra:

Os travestis não são necessariamente homossexuais, mas se identificam fortemente com as pessoas do outro sexo. De certo modo, Norman queria ser como a mãe, da mesma forma que desejava que a mãe se tornasse uma parte dele próprio. (BLOCH, 2013, p. 147).

Intrinsecamente, não há tanta diferença quanto à incompreensão de ambos os Normans diante da comunidade. Ainda que sejam personagens de narrativas destinadas a públicos distintos, eles representam o inconveniente presente na ou desde a infância. 


\section{Pluft}

Em 1955, no Brasil, é concluído o texto de Maria Clara Machado, que também dirigiu a primeira montagem de Pluft, o Fantasminha, no seu teatro O Tablado, no Rio de Janeiro. Pluft, sua mãe, Senhora Fantasma (ou Dona Fantasma, no livro adaptado), e o Tio Gerúndio "vivem" no sótão de uma casa abandonada, perto do mar. Nesta dramaturgia, o mote da visibilidade entre mundos de vivos e mortos repete-se, mas do ponto de vista do outro lado: o menino-fantasma teme os humanos.

Já na segunda cena, a pergunta feita por Pluft, “- Mamãe, gente existe?” (MACHADO, 2009a, paginação irregular), resume toda a história de negação e receio pela alteridade por parte do fantasminha. “- Mamãe, eu tenho tanto medo de gente!” (MACHADO, 2009a, paginação irregular), ele complementa. Ela responde-lhe que gente existe e que gente é que tem medo de fantasma e invoca a figura paterna para expor seu discurso opressor e que, à época em que foi escrita a peça, poderia ser considerado politicamente correto, contra a sensibilidade do fantasminha: "- Se seu pai fosse vivo, Pluft, você apanharia uma surra com esse medo bobo." (MACHADO, 2009a, paginação irregular). Mesmo que o pai não esteja "vivo" (ele morreu e virou celofane), a lembrança de sua figura mantém o papel, como o pai em ParaNorman, de regulação do comportamento da criança. O pai de Pluft era o Fantasma da Ópera ${ }^{20}$ quando ele, a mãe e Pluft moravam em um teatro; também era considerado corajoso porque assombrava as pessoas, ao contrário do filho temeroso.

É importante destacar que a primeira ação e aparição de Pluft no espetáculo é do personagem brincando com um barco. Então, Pluft troca o barco, que é um brinquedo identificado com meninos e relacionado aos marinheiros, também, representações de masculinidade, por uma velha boneca de pano. A boneca é o dispositivo que lhe aflige sobre a existência de gente e leva ao questionamento feito à mãe. A troca dos brinquedos como cena inaugural para o personagem mostra que o fantasma, ainda que seja tratado pelo gênero masculino, apresenta uma ambivalência e imprecisão de gênero: tanto faz que brinque com objeto masculinizado ou feminilizado. Há uma transição sem conflito.

O desenrolar da história acontece com a chegada do marinheiro Perna de Pau, o antagonista, que sequestrara a menina Maribel, neta do Capitão Bonança Arco-íris. A intenção do vilão é roubar o tesouro do navio fantasma do avô de Maribel, que estaria escondido na casa

\footnotetext{
${ }^{20}$ A peça promove a intertextualidade com o romance escrito pelo francês Gaston Leroux O Fantasma da Ópera (Le Fantôme de L'Opéra), lançado em 1910 e considerado sua obra-prima.
} 
da beira da praia onde estão os fantasmas. À procura do Perna de Pau, surgem três marinheiros, João, Julião e Sebastião, que precisam salvar a menina. Assim como em ParaNorman, a ameaça em Pluft, o Fantasminha não é o estranho, mas o humano.

Como Maribel é instalada e imobilizada em cárcere privado no mesmo sótão onde está a família fantasma, ela e Pluft se conhecem e reconhecem-se como diferentes e sem medo. Pluft descobre que seu Tio Gerúndio era o fantasma do navio (fantasma) do avô da menina. Assim, os dois acabam formando uma amizade: "Maribel cutuca o fantasminha e acha graça de ele ser diferente dela". (MACHADO, 2009a, paginação irregular). Ao fim e ao cabo, através da parceria, quando essas diferenças são superadas entre os dois e eles se entendem através da infância em comum, Pluft e outros fantasmas conseguem assombrar e correr o marinheiro meio pirata vilão interessado não apenas no tesouro, mas em se casar com a menina. A pedofilia sugerida é mais uma ocorrência politicamente incorreta e datada na obra de Maria Clara Machado. Há mais uma. No livro que adapta a peça, ela apresenta os três marinheiros como cachaceiros: “(...) paravam em todo botequim que encontravam para tomar coragem dentro de um copo de pinga./ Esta é uma maneira muito comum de tomar coragem”. (MACHADO, 2009b, paginação irregular).

Em certo momento, um dos marinheiros, ao se deparar com Pluft, chama-o de monstro. O fantasma se ofende: “- Marinheiro bobo, sem educação! Monstrinho é você, seu cara de gente! Vou contar à mamãe que você me chamou de monstrinho.” (MACHADO, 2009a, paginação irregular). A ofensa de monstro, ainda que seja um chiste que reforça a distinção e as fronteiras entre tipos góticos, é a mesma que a aberração atribuída ao menino Norman pelos colegas de escola. O mostro, tanto lá quanto na peça, é a evidência do queer incompreendido, tanto que lhes atribuem uma caracterização injuriante. Pluft precisa aprender a ser fantasma no que é entendido como tal. Assim como Norman Bates é descrito na abertura do livro de Bloch como um homem temeroso vendo o mundo protegido pela janela, Pluft, no livro em prosa, é apresentado de maneira muito parecida e, igualmente, incitado pela figura materna; na peça, a mãe é um fantasma, no livro de suspense, uma presença fantasmagórica. Diz o narrador de Pluft, o Fantasminha: "Pois bem, Pluft era um fantasminha muito medroso./ Olhava pela janela, via a praia, o mar tão azul e grande, e tremia de medo.” (MACHADO, 2009b, paginação irregular). Em Bloch: "Norman ouviu o som e estremeceu./ Parecia que alguém estava batendo na vidraça./ Ele levantou os olhos, fez menção de se erguer (...). Percebeu que o barulho era apenas a chuva." (2013, p. 8). 
Um outro indicativo da ambivalência de Pluft diz respeito às montagens do espetáculo. A peça, vinculada à escola de teatro O Tablado, fundada pela própria Maria Clara Machado, em 1951, teve oito montagens ${ }^{21}$ naquele espaço, entre 1955 e 2013, quase todas com intérpretes mulheres para Pluft. A feminilização do personagem não é apontada nas rubricas do texto dramatúrgico, mas tornou-se uma tradição, que reforça esse intermédio de gêneros na caracterização do fantasma. Uma única exceção, entre as montagens oficiais, é a de 1985: pela primeira e única vez, dentro do Tablado, um homem, o ator Luís Carlos Tourinho, interpretou Pluft.

Maria Clara Machado escreveu peças infantis para formar atores e público e, segundo o crítico teatral Sábato Magaldi, seus textos não "são apenas boas peças infantis: incluem-se entre os melhores textos produzidos pela dramaturgia brasileira." (2016, paginação irregular). Em um artigo publicado originalmente em 1969, ele traz à discussão um provável movimento de aproximar o teatro infantil da realidade:

Ainda me parece bizantina a discussão se o teatro infantil deve abolir fadas e bruxas, e voltar-se para a realidade. O Fantasminha que tem medo de gente e a bruxinha boa, de Maria Clara Machado, só podem fazer bem à sensibilidade infantil." (MAGALDI, 2016, paginação irregular).

Ele refere, nos dois exemplos, ao deslocamento dos papeis previstos a um fantasma e uma bruxa. De 1958, ou seja, escrita e montada no mesmo Tablado, no embalo do sucesso de Pluft... ${ }^{22}$, peça A bruxinha que era boa, assim como o fantasma medroso, também inverte o esperado a um personagem gótico ao apresentar Angela, uma bruxinha boa que precisava conviver com bruxos e bruxas malvados. ${ }^{23}$ Maria Clara Machado explora clichês de histórias para crianças, como a bruxa e o fantasma, descrevendo-os também como crianças para apontarlhes desvios e aproximá-los da diversidade de comportamentos possíveis na infância. Uma gag da peça Pluft... também apresentada na adaptação em prosa mostra o fantasminha contemplando, pela primeira vez, uma pessoa, Maribel, chorar. Ele pede à mãe para também chorar, ao que ela lhe diz: “- Ora, Pluft, fantasma não chora, senão derrete”. (MACHADO, 2009b, paginação irregular). Trata-se de um chiste que remete ao clássico "meninos não choram" dito às crianças do sexo masculino quando apresentam alguma sensibilidade e que está muito próximo do esforço da mãe de tornar Pluft corajoso. Dona Fantasma não faz bullying

\footnotetext{
${ }^{21} \mathrm{http} / / /$ otablado.com.br/espetaculos/1/pluft-o-fantasminha acessado em 31/5/2020

22 “(...) a peça ganhou o prêmio da Associação Paulista de Críticos Teatrais, como melhor espetáculo amador e melhor autor nacional. Outros prêmios também viriam depois." (MACHADO, 2009b, paginação irregular).

${ }^{23}$ Poderia ser realizada, ainda, uma aproximação entre Aggie, a suposta bruxa criança não compreendida de ParaNorman, e a bruxinha Angela, também deslocada.
} 
apenas com o filho, mas com os três marinheiros meio medrosos cuja coragem encontram na bebida. Quando eles se espantam diante dos fantasmas no sótão, fala: “ - Ridículo (...) uns homens deste tamanho com medo de um fantasminha". (MACHADO, 2009b, paginação irregular). Assim, a mãe de Pluft, invocando ou não o falecido marido, reproduz as imposições de gênero como o pai do menino Norman, ao longo de toda a trama, sendo este um dos conflitos de ambos os textos.

\section{Conclusão}

Ainda que a monstruosidade lhes ofenda, ela é o aspecto garantidor da queeridade de Norman e Pluft, e a partir da qual se discute a alteridade em ambas as obras: a relação do fantasma com as gentes, e da gente [Norman] com os vivos que lhe assombram. Ao desenvolverem a temática do sobrenatural, como o fora da norma, o desnaturalizado, filme, livro, peça e texto em prosa expõem as crianças desencaixadas dos papeis que lhes são previamente atribuídos, principalmente, pela instituição familiar. Norman torna-se visível em sua integridade pelo fantasma da avó e relaciona-se melhor com os fantasmas da rua do que com os próprios pais; Pluft só entende sua diferença quando Maribel compreende-o assim, sem a necessidade de assombrá-la - segundo a norma - como lhe exigia a mãe. "Os monstros, felizmente, existem não para nos mostrar o que não somos, mas o que poderíamos ser." (GIL, 2000, p. 168).

Em Pluft..., o fantasma é humanizado para satisfazer a fábula em sua ludicidade, e o vilão é o homem, o pirata, não o sobrenatural. Já em ParaNorman, o menino assume a figura de monstro comunitário que precisa compreender o monstro histórico, a bruxa e suas formas assustadoras. Os vilões não são os fantasmas, compreende-se ao final, mas a comunidade intolerante. Em ambos os casos, o que falta é a visibilidade do queer. Qual a dificuldade? Os limites, que se rasuram e causam dúvida, mancham a antítese homem-mostro que é a mesma lógica do menino-menina, indefinida no caso de Minha Vida em Cor-de-Rosa. É aí que o queer se estabelece para fortalecer um discurso alternativo: “eles são híbridos que perturbam, híbridos cujos corpos externamente incoerentes resistem a tentativas para incluí-los em qualquer estruturação sistemática”. (COHEN, 2000, p. 28). Como disse o diretor e roteirista de ParaNorman: "Eu quis que ParaNorman fosse direcionado às questões que realmente nos 
afetam quando estamos crescendo: bullying, adequação, formação de identidade, e, claro, invasão zumbi." ${ }^{24}$ (BUTLER, 2012, p. 16).

\section{REFERÊNCIAS}

ANDALZÚA, Gloria. To(o) Queer the Writer: Loca, Escrita y Chicana. In: KEATING, A. (Ed.) The Gloria Andalzúa Reader. Durhan e Londres: Duke University Press, 2009. p. 163175.

BLOCH, Robert. Psicose. Rio de Janeiro: DarkSide Books, 2013.

BUTLER, Chris et alii. The Art and making of ParaNorman. San Francisco: Chronicle Books, 2012.

BUTLER, Judith. Corpos que importam. Trad. de Verônica Daminelli e Daniel Yago Françoli. São Paulo: n-1 edições; Crocodilo Edições, 2019.

COHEN, Jeffrey Jerome. A cultura dos monstros: sete teses. In: TADEU, da S. (Org.). Pedagogia dos monstros - os prazeres e os perigos da confusão de fronteiras. Belo Horizonte: Autêntica, 2000. p. 23-60.

GAGA, Lady (@ladygaga).To every little monster on the planet who feels different. So do I. And we have each other. Forever. Instagram, 9 de abril de 2018.

https://www.instagram.com/p/BhVx0RyB1xX/?igshid=991o088u5d7j

GIL, José. Metafenomenologia da monstruosidade: o devir-mostro. In: TADEU, da S. (Org.). Pedagogia dos monstros - os prazeres e os perigos da confusão de fronteiras. Belo Horizonte: Autêntica, 2000. p. 165-184.

HOGLE, Jerrold E. Introduction: the Gothic in western culture. In: HOGLE, J. (Ed.) The Cambridge Companion to Gothic Fiction. Cambridge University Press, 2002. p. 1-20.

JUNQUEIRA, Ivan. A Sagração dos Ossos. Rio de Janeiro: Civilização Brasileira, 1994.

KIMMEL, Elizabeth Cody. ParaNorman. São Paulo: Salamandra, 2012.

LORDE, Audre. Irmã outsider. Belo Horizonte: Autêntica Editora, 2019.

MACHADO, Maria Clara. Pluft, o Fantasminha e outras peças. Rio de Janeiro: Nova Fronteira: 2009a.

MACHADO, Maria Clara; LIMA, Graça. Pluft, o Fantasminha. Rio de Janeiro: Nova Fronteira, 2009b.

\footnotetext{
24 "I wanted ParaNorman to address the kinds of issues that really affect us when we're growing up: bullying, fitting in, the formation of identity, and, of course, zombie invasion."
} 
MAGALDI, Sábato. Amor ao teatro: Sábado Magaldi. São Paulo: Edições Sesc São Paulo, 2016.

MINHA vida em cor-de-rosa. Direção: Alain Berliner, França: Classiciline, 1997. 1 DVD.

MISKOLCI, Richard. Teoria Queer: um aprendizado pelas diferenças. Belo Horizonte: Autência: UFOP, 2012.

PARANORMAN. Dirigido por Chris Butler e Sam Fell, Estados: Laika Films, 2012. 1 DVD.

PRECIADO, B. Paul. Um apartamento em Urano. Rio de Janeiro: Editora Zahar, 2020.

PSICOSE. Dirigido por Alfred Hitchcock, Estados Unidos: Paramount Pictures, 1960. 1 DVD.

SEDGWICK, Eve Kosofsky. A Epistemologia do Armário. cadernos pagu, Campinas, n. 28, jan.-jun., 2007. p. 19-54.

SCHIFF, Stacy. As bruxas - Intriga, traição e histeria em Salem. Rio de Janeiro: Editora Zahar, 2019.

Recebido em 28/9/2020.

Aceito em 14/12/220. 